\title{
Responses of woody species to spatial and temporal ground water changes in coastal sand dune systems
}

\author{
C. Máguas ${ }^{1}$, K. G. Rascher ${ }^{1,3}$, A. Martins-Loução ${ }^{1}$, P. Carvalho ${ }^{1,2}$, P. Pinho ${ }^{1}$, M. Ramos $^{1}$, O. Correia ${ }^{1}$, and \\ C. Werner $^{3}$ \\ ${ }^{1}$ University of Lisbon, Faculty of Sciences, Centre for Environmental Biology, Campo Grande, Lisbon, Portugal \\ ${ }^{2}$ Division of Plant and Crop Sciences, University of Nottingham, MM, UK \\ ${ }^{3}$ Experimental and Systems Ecology, University of Bielefeld, Universitätsstrasse 25, 33615 Bielefeld, Germany
}

Received: 27 January 2011 - Published in Biogeosciences Discuss.: 22 February 2011

Revised: 22 September 2011 - Accepted: 23 November 2011 - Published: 22 December 2011

\begin{abstract}
In spite of the relative importance of groundwater in costal dune systems, studies concerning the responses of vegetation to ground water (GW) availability variations, particularly in Mediterranean regions, are scarce. Thus, the main purpose of this study is to compare the responses of co-occurring species possessing different functional traits, to changes in GW levels (i.e. the lowering of GW levels) in a sand dune ecosystem. For that, five sites were established within a $1 \mathrm{~km}^{2}$ area in a meso-mediterranean sand dune ecosystem dominated by a Pinus pinaster forest. Due to natural topographic variability and anthropogenic GW exploitation, substantial variability in depth to GW between sites was found. Under these conditions it was possible to identify the degree of usage and dependence on GW of different plant species (two deep-rooted trees, a drought adapted shrub, a phreatophyte and a non-native woody invader) and how GW dependence varied seasonally and between the heterogeneous sites. Results indicated that the plant species had differential responses to changes in GW depth according to specific functional traits (i.e. rooting depth, leaf morphology, and water use strategy). Species comparison revealed that variability in pre-dawn water potential $\left(\Psi_{\text {pre }}\right)$ and bulk leaf $\delta^{13} \mathrm{C}$ was related to site differences in GW use in the deeprooted (Pinus pinaster, Myrica faya) and phreatophyte (Salix repens) species. However, such variation was more evident during spring than during summer drought. The exotic invader, Acacia longifolia, which does not possess a very deep root system, presented the largest seasonal variability in $\Psi_{\text {pre }}$ and bulk leaf $\delta^{13} \mathrm{C}$. In contrast, the response of Corema album, an endemic understory drought-adapted shrub, seemed
\end{abstract}

Correspondence to: C. Máguas

(cmhanson@fc.ul.pt) to be independent of water availability across seasons and sites. Thus, the susceptibility to lowering of GW due to anthropogenic exploitation, in plant species from sand dunes, is variable, being particularly relevant for deep rooted species and phreatophytes, which seem to depend heavily on access to GW.

\section{Introduction}

Vegetation-groundwater interactions are the focus of renewed interest, particularly in semi-arid areas, reflecting the current trend towards a more holistic approach and integrated management of natural resources (e.g. Antonellini and Mollema, 2010; Brolsma et al., 2010; Xie et al., 2011). Groundwater (GW) extraction and surface water diversions produce dramatic changes in stand structure and species composition, as well as plant functioning (e.g. Valentini et al., 1995; Stromberg et al., 1996; Stromberg and Patten 1990; Lite and Stromberg, 2005), thereby significantly altering groundwater-dependent ecosystems (e.g.; Murray et al., 2003; Lamontagne et al., 2005). To date, very few studies have had the opportunity to use artificial lowering of GW levels at the ecosystem scale, in order to monitor the plant community response to changing GW levels (e.g. Stromberg and Patten, 1990). Since 2001, a pine forest, located in the western coastal region of Portugal, has been subjected to artificial lowering of the GW table, as a result of industrial water exploitation, providing excellent experimental conditions to study the responses of the plant community to variations in GW availability.

Published by Copernicus Publications on behalf of the European Geosciences Union. 
The patterns of use and redistribution of soil water by plant species have a considerable impact on hydrological cycles in terrestrial ecosystems (Jackson et al., 2000). For example, within the same community, species may differ substantially in rooting depth and water consumption, in such a way that shifts in species composition can significantly alter patterns of ecosystem water use (Canadell and Zedler, 1995; Canadell et al., 1996; Jackson et al., 1995, 2000). However, the water sources and/or depth of soil water uptake by plants have traditionally been difficult to assess (i.e. Ehleringer and Dawson, 1992). Currently, considerable progress identifying plant water sources has been achieved by means of stable isotope analyses (oxygen and/or hydrogen), provided that water sources have distinct isotopic signatures (Phillips and Gregg 2001; Ehleringer and Dawson, 1992; Dawson, 1993; Corbin et al., 2005). Since there is no isotopic fractionation by plant roots during water uptake (White et al., 1985), the isotopic composition of plant xylem water reflects the isotopic composition of water taken up by the plant (e.g. Dawson and Ehleringer, 1991; Dawson, 1993; Dawson and Pate, 1996; Corbin et al., 2005). In Mediterranean dune systems, drought is exacerbated by the low water holding capacity of sandy soils and by the likelihood of high salinity and possibility of sea water intrusion (Garcia Novo et al., 2004; Zunzunegui et al., 2005; Costelloe et al., 2008; Antonellini and Mollema, 2010). Moreover, in sand dunes, similar to what has been observed in deserts and semi-arid zones, small-scale variations in vegetation density, soil surface cover, and soil texture can determine the amount of water and nutrients available to plants (Rosenthal et al., 2005).

Strong seasonality conditions, such as those observed in the Mediterranean region, often raise the question of how distinct are species' responses to the shortage of a particular water source. The main objective of this work is, thus, to compare the responses of co-occurring species possessing different functional traits, to changes in $\mathrm{GW}$ levels (i.e. the lowering of GW levels) in a sand dune ecosystem. To achieve this, species specific responses to the combined stresses of seasonal drought and changes in GW level were evaluated. For that, each plant species was compared across five different sites differing in GW depth, but all located within a $1 \mathrm{~km}^{2}$ continuous area.

Given the particular conditions of artificial lowering of GW levels in this study, we hypothesized that species from functional groups which have consistent access to GW (i.e. phreatophytes, and trees with deep, well-developed root systems) would be less affected by seasonal drought but more susceptible to the artificial lowering of the GW levels. In contrast, we expected that drought adapted shrubs with limited or no access to GW would be less affected by the artificial lowering of GW levels. These hypotheses were tested by comparing five species with different water use strategies and rooting profiles: a deep rooted pine (Pinus pinaster), an endemic shrub (Corema album), native (Myrica faya) and invasive (Acacia longifolia) woody understory trees, and a

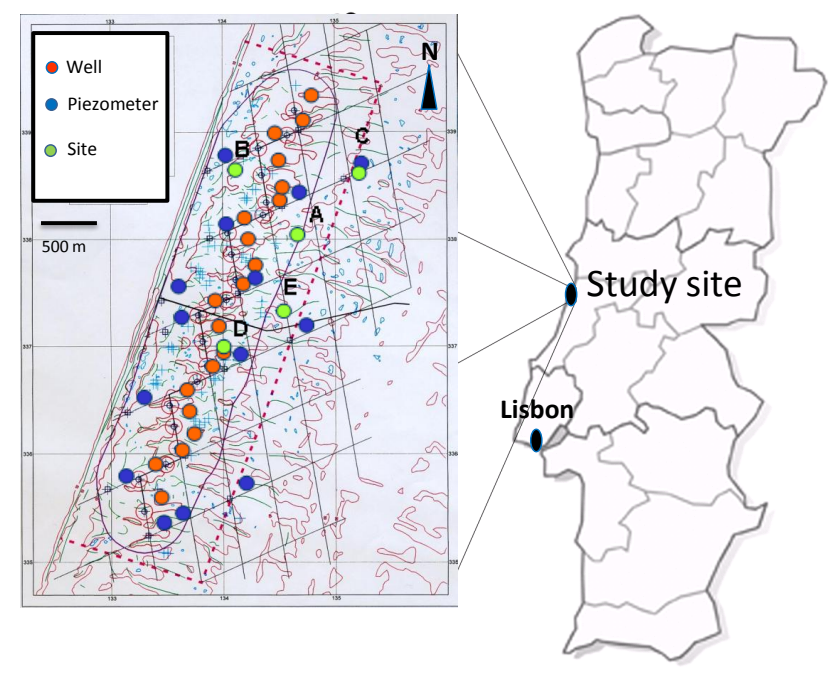

Fig. 1. Map of Osso da Baleia, Portugal indicating locations of the water extraction line, wells, piezometers and field site locations.

phreatophytic willow (Salix repens ssp. argentea), a plant species that is dependent upon GW and very sensitive to changes in this water source.

\section{Material and methods}

\subsection{Site description}

The study was conducted at Osso da Baleia in Carriço, Pombal, Portugal $\left(40^{\circ} 0^{\prime} 3.47^{\prime \prime} \mathrm{N}, 08^{\circ} 54^{\prime} 14.73^{\prime \prime} \mathrm{W}\right)$, in coastal dunes with some patches of mature pine (Pinus pinaster) forest (Fig. 1). Presently, human influence in this coastal dune is low, with the exception of GW exploitation for the construction of natural gas reservoirs, by the National Electricity Network (REN). Systematic GW exploitation has been carried out since 2001 by REN. Water is extracted at 20 wells along a $4 \mathrm{~km}$ long north-south line ( $\sim 600 \mathrm{~m}$ from the coast) affecting the GW levels in $8.2 \mathrm{~km}^{2}$ of dune habitat (Fig. 1). Water extraction at all wells is limited to $600 \mathrm{~m}^{3} \mathrm{~h}^{-1}$ and maximum lowering of the ground water table is restricted to $5 \mathrm{~m}$ at each well. A network of wells and piezometers (17 in total) allowed for a spatially explicit determination of groundwater depth throughout the study area.

For this study, five sites (letters A to E) were selected nearby to the water extraction line in an area of approximately $1 \mathrm{~km}^{2}$ (Fig. 1); although closely located, each site can be distinguished by its unique GW dynamics. Microclimatic data were obtained from a Campbell Scientific climate station (Shepshead, UK) which monitored wind velocity and direction, precipitation, air humidity, temperature and solar radiation in the study area. 


\subsection{Plant species}

Functionally distinct species were selected in order to assess the overall community effect of GW lowering: (1) Pinus pinaster - a native evergreen tree species (archeophyte) with a very broad distribution in the Mediterranean basin, particularly in the coastal areas of France and the Iberian Peninsula; (2) Corema album - an evergreen shrub of the Ericacea family, endemic to the Atlantic coast of the Iberian Peninsula; (3) Salix repens ssp. argentea - an important species of the dune slack habitat, with the southern limit of its distribution in this region; (4) Myrica faya - a naturalized, fast-growing evergreen shrub or small tree with the capacity to fix atmospheric nitrogen; (5) the exotic invasive Acacia longifolia - which has characteristic traits of a successful invader, such as a rapid growth rate sustained by efficient resource acquisition (high $\mathrm{N}$-uptake and symbiotic $\mathrm{N}$-fixation), and high seed production. The selected woody native and non-native species present differential tolerances to drought conditions: Pinus pinaster and Corema album are typical drought-adapted species, in opposition to Salix repens, which is a phreatophyte and therefore particularly dependent on GW.

\subsection{Water potential}

Predawn leaf water potential ( $\left.\Psi_{\text {pre }}\right)$ was determined in situ with a Scholander-type pressure chamber (Scholander et al., 1965) (Manofrígido, Lisbon, Portugal) to evaluate the water status of each species at each site in spring (May) and summer (August) 2005. Measurements were conducted on 5 individuals of each species in each of the sites, with the exception of $P$. pinaster, i.e., a maximum of 25 plants per site. However, not all five species were present at all locations, and thus a total of 90 plants were measured in each season.

\subsection{Identification of water-sources and their differential utilization by plants}

To identify the seasonal water sources used by plant species, the oxygen isotopic composition $\left(\delta^{18} \mathrm{O}\right)$ of precipitation (single rain events and cumulative monthly precipitation collected from plastic containers that were protected against evaporation by being located in a wood-housing and with a layer of paraffin wax on the surface of the collected water) and GW (obtained directly from piezometers and extraction wells from REN) were analysed monthly using an ISOPrime isotope ratio mass spectrometer (IRMS) coupled to an automatic water/ $\mathrm{CO}_{2}$ equilibration system (Multiflow, GV Instruments, UK). In order to avoid any type of fractionation due to evaporation, collection of the monthly and rain-event precipitation was carried out by local REN personnel. At the end of each season, $10 \mathrm{~cm}$ twigs of five plants per species per site were collected, sealed in glass tubes and immediately placed on dry ice to avoid any water evaporation and conse- quent isotopic fractionation. Xylem water was then extracted under vacuum in the laboratory. The isotopic composition was determined by on an ISOprime IRMS (GV Instruments, $\mathrm{UK}$ ) coupled to an automatic water/ $\mathrm{CO}_{2}$ equilibration system (Multiflow, GV Instruments, UK). Isotopic composition is expressed in delta notation as $\delta^{18} \mathrm{O}(\%)$ in relation to the international standard Vienna SMOW (Eq. 1).

$\delta^{18} \mathrm{O}_{\text {sample }}=\left(R_{\text {sample }} / R_{\text {standard }}-1\right)$

where $R_{\text {sample }}$ and $R_{\text {standard }}$ are the ${ }^{18} \mathrm{O} /{ }^{16} \mathrm{O}$ ratios of the sample and the standard, respectively. The overall precision of the process and sample analysis was $\pm 0.1 \%$.

\subsection{Two-source mixing model for determination of plant water sources}

Seasonally, we used the two-compartment linear mixing model of Phillips and Gregg (2001) to estimate the percentage of xylem water derived from groundwater $\left(P_{\mathrm{GW}}\right)$ :

$P_{\mathrm{GW}}=\frac{\delta^{18} \mathrm{O}_{\mathrm{xylem}}-\delta^{18} \mathrm{O}_{\text {rain }}}{\delta^{18} \mathrm{O}_{\mathrm{GW}}-\delta^{18} \mathrm{O}_{\text {rain }}}$

where $\delta^{18} \mathrm{O}_{\mathrm{xylem}}$ is the isotope ratio of water extracted from the plants' xylem, $\delta^{18} \mathrm{O}_{\text {rain }}$ is the mean seasonal isotope value for rain water and $\delta^{18} \mathrm{O}_{\mathrm{GW}}$ is the mean isotope value for groundwater. Stable isotope mixing models are often used to quantify source contributions to a mixture. With the mixing model developed by Phillips and Gregg (2001), we may calculate the mean and the standard error of the fractional contributions based on the uncertainty generated by the variability of both sources (Phillips and Gregg, 2001).

Model application results indicate that some individual plants had greater than $100 \%$ or less than $0 \%$ dependence on groundwater. This can result from either neglecting a third water source or from errors in xylem or source water $\delta^{18} \mathrm{O}$ determination (Phillips and Gregg, 2001). Plant values that were outside the 0 to $100 \%$ range by less than $30 \%$ (e.g. between $-30 \%$ and $130 \%$ ) were subsequently assigned a value of either 0 or $100 \%$ dependence on groundwater. When the mixing-model indicated values of groundwater dependence of less than $-30 \%$ or greater than $130 \%$ data were excluded from further analyses.

\subsection{Carbon isotope discrimination in plant material}

At the end of each season, south-facing sun-exposed leaves $(n=5)$ per species per site were collected, dried at $60^{\circ} \mathrm{C}$ for at least $72 \mathrm{~h}$, ground to a fine powder in a ball mill (Retsch MM 2000, Germany) and analyzed for $\delta^{13} \mathrm{C}$ in continuous flow mode on an Isoprime IRMS (GV Instruments, UK) coupled to an automatic sample preparation system elemental analyser EUROEA (EuroVector, Italy). Results are expressed in $\delta$ notation and were standardized against Vienna PDB as the international standard (Eq. 3).

$\delta^{13} \mathrm{C}_{\text {sample }}=\left(R_{\text {sample }} / R_{\text {standard }}-1\right)$ 
where $R_{\text {sample }}$ and $R_{\text {standard }}$ are the ${ }^{13} \mathrm{C} /{ }^{12} \mathrm{C}$ ratios of the sample and the standard, respectively. The precision of the repeated measurement was $0.05 \%$.

\subsection{Mapping spatial and temporal variation in GW}

In spring and summer, GW level (relative to sea level) was calculated using data obtained from wells and piezometers. Data were interpolated within the study area using ordinary kriging by calculating variograms for each season (Cerena, 2000, geoMs - Geostatistical Modelling Software). A spherical function describing the spatial correlation in the data (nugget effect $=0$, maximum range $=3200 \mathrm{~m}$ and anisotropy in the NE-SW) was fitted to the variograms and then used to interpolate and generate a continuous map of GW level. Next, a map detailing the distance to GW was calculated as the difference between the GW level map and the ground surface topography, calculated from a digital terrain model detailing the topography of the study area. Mapping and outputs were produced in ArcGis (ESRI, 2008, ArcMap v. 9.2).

\subsection{Statistical analysis}

Within species, one-way ANOVA was used to determine the effect of site, season and the site*season interaction on bulk leaf $\delta^{13} \mathrm{C}, \Psi_{\text {pre }}$ and GW use. GW use data was square root transformed before analysis to satisfy the ANOVA assumptions of normality and homogeneity of variance. Linear regression was used to determine the relationships between $\delta^{13} \mathrm{C}$ and $\Psi_{\text {pre }}$ and GW use. All analyses were conducted in R 2.6.2 (R Core Development Team, 2008).

\section{Results}

\subsection{Climate}

Osso da Baleia is located in a meso-mediterranean climatic region (Fig. 1). The year 2005 was particularly dry when compared with the last 30 years with precipitation distribution following the characteristic Mediterranean pattern: high rainfall during spring and fall and a relatively early onset of drought in mid-May with only a few minor rainfall events $(<10 \mathrm{~mm})$ until October (Fig. 2a). Minimum and maximum daily temperatures occurred in February $\left(-0.6^{\circ} \mathrm{C}\right)$ and $\mathrm{Au}-$ gust $\left(38.5^{\circ} \mathrm{C}\right)$ respectively (Fig. $\left.2 b\right)$.

\subsection{Plant water sources: species differences and seasonal variability}

Precipitation $\delta^{18} \mathrm{O}$ values varied significantly between spring and summer. Moreover, irrespective of the season, the isotopic signature of GW was always distinct from that of precipitation; with GW being more depleted than precipitation (Fig. 3). This allowed the evaluation of the relative uptake of precipitation and GW sources by analysis of the iso-

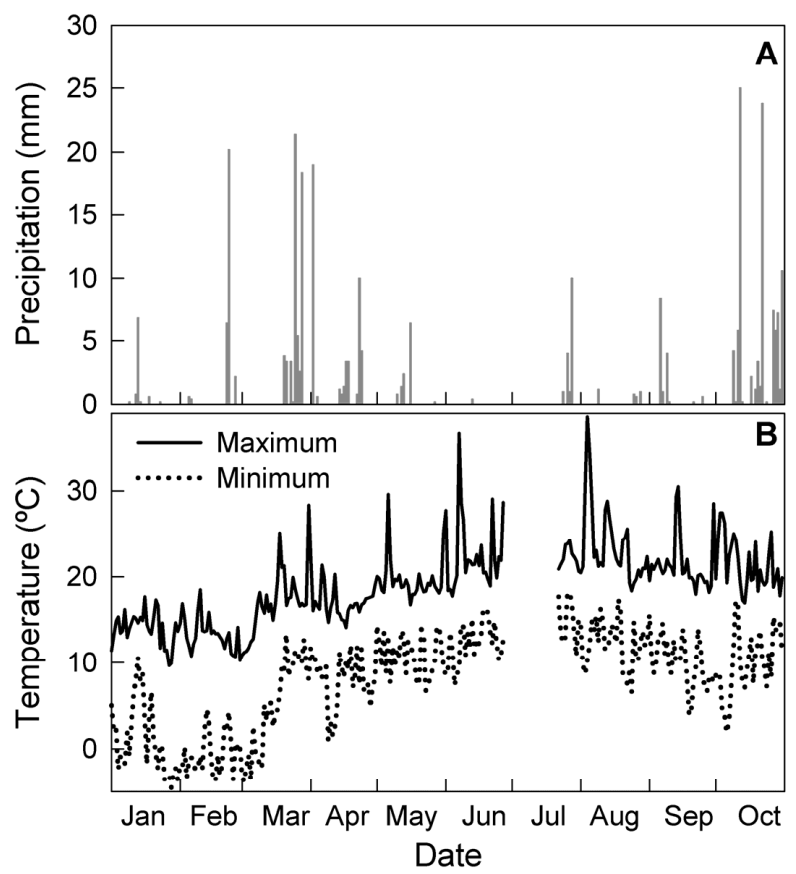

Fig. 2. January through October 2005 (A) precipitation and (B) temperature for Osso da Baleia, Portugal. Data from 28 June to 21 July 2005 are missing due to data logger failure.

topic composition of xylem water. $\mathrm{GW} \delta^{18} \mathrm{O}$ varied slightly throughout the year and was more variable in spring than summer (Fig. 3a, b) but the mean value remained relatively constant (between $-4.2 \%$ and $-4.3 \%$, Fig. 3 ). During summer drought, which was characterized by no significant precipitation and very high temperatures, there was likely strong ${ }^{18} \mathrm{O}$ enrichment in soil water, presumably due to high evaporation in the top soil layers.

Greater differences in xylem water $\delta^{18} \mathrm{O}$ between plant species were found in summer compared to spring. Xylem water $\delta^{18} \mathrm{O}$ values indicated that most species utilized a mixture between GW and precipitation during spring (Fig. 3a). During summer drought, due to the combination of decreasing GW levels and no significant precipitation, plants tended to have xylem water $\delta^{18} \mathrm{O}$ values which differed from GW signatures, (Fig. 3b). This observation was particularly relevant for the shallow rooted A. longifolia, which had a large number of individuals with relatively enriched xylem water.

In addition to functional variability between the species, a very high variability in GW utilization was observed between the five sites, revealing differences in access to GW within the $1 \mathrm{~km}^{2}$ study area. Xylem water $\delta^{18} \mathrm{O}$ from sites $\mathrm{A}, \mathrm{B}$ and $\mathrm{C}$ indicated a greater utilization of $\mathrm{GW}$, whereas plants at sites $\mathrm{D}$ and $\mathrm{E}$ appeared to use a more even mixture of $\mathrm{GW}$ and precipitation. During summer, with the lowering of GW, plants in sites $\mathrm{A}$ and $\mathrm{B}$ showed a larger enrichment in $\delta^{18} \mathrm{O}$ (relative to spring values), indicating a more limited use of GW. 
Table 1. P-values from Analysis of Variance with (A) bulk leaf $\delta^{13} \mathrm{C}$, (B) predawn xylem water potential ( $\left.\Psi_{\text {pre }}\right)$ and (C) groundwater use as response variables and Site, Season and the Site*Season interaction as predictor variables. ANOVA was conducted for each species and response variable independently. Groundwater use data were square root transformed before analysis to satisfy the ANOVA assumptions of normality and homogeneity of variance. Significant values $(\alpha=0.05)$ are shown in bold.

\begin{tabular}{lrrrrr}
\hline (A) & \multicolumn{5}{c}{$\delta^{13} \mathrm{C}(\%)$} \\
\hline Site & A. longifolia & C. album & M. faya & S. repens & P. pinaster \\
Season & $<\mathbf{0 . 0 0 1}$ & $<\mathbf{0 . 0 0 1}$ & $<\mathbf{0 . 0 0 1}$ & $<\mathbf{0 . 0 0 1}$ & $<\mathbf{0 . 0 0 1}$ \\
Site * Season & 0.027 & 0.981 & 0.800 & 0.867 & 0.380 \\
\hline (B) & 0.424 & 0.436 & 0.823 & 0.558 & 0.777 \\
\hline \multicolumn{5}{c}{$\Psi_{\text {Predawn }}(\mathrm{MPa})$} \\
\hline Site & A. longifolia & C. album & M. faya & S. repens & P. pinaster \\
Season & $<\mathbf{0 . 0 0 1}$ & 0.133 & $<\mathbf{0 . 0 0 1}$ & $<\mathbf{0 . 0 0 1}$ & nd \\
Site * Season & $<\mathbf{0 . 0 0 1}$ & $\mathbf{0 . 0 0 1}$ & $<\mathbf{0 . 0 0 1}$ & $\mathbf{0 . 0 0 6}$ & nd \\
\hline (C) & $\mathbf{0 . 0 0 2}$ & 0.183 & $<\mathbf{0 . 0 0 1}$ & $<\mathbf{0 . 0 0 1}$ & nd \\
\hline \multicolumn{7}{c}{ Groundwater Use } & $(\%)$ & \\
\hline Site & A. longifolia & C. album & M. faya & S. repens & P. pinaster \\
Season & $\mathbf{0 . 0 0 1}$ & 0.866 & $<\mathbf{0 . 0 0 1}$ & $\mathbf{0 . 0 0 4}$ & $<\mathbf{0 . 0 0 1}$ \\
Site * Season & $\mathbf{0 . 0 0 6}$ & 0.652 & 0.168 & $\mathbf{0 . 0 4 4}$ & 0.522 \\
\hline & 0.153 & 0.305 & 0.084 & 0.128 & 0.158 \\
\hline
\end{tabular}

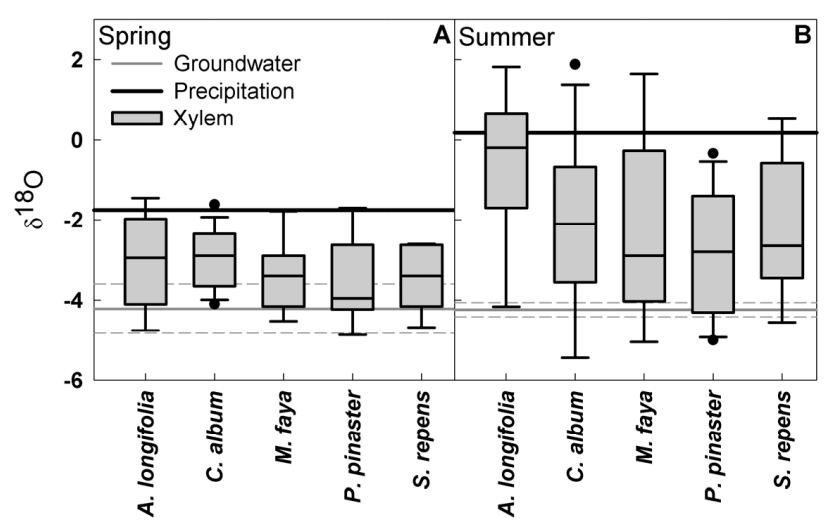

Fig. 3. $\delta^{18} \mathrm{O}(\%$ ) of xylem water (boxplot), precipitation (black line) and groundwater (grey line) in (A) spring (May) and (B) summer (August). Boxplots denote the 10th, 25th, median, 75th and 90th percentiles of the xylem $\delta^{18} \mathrm{O}$ for each species. Outlying values are indicated by solid circles denoting the 5 th and 95th percentiles. Precipitation $\delta^{18} \mathrm{O}$ for spring is the mean value of the two major rainfall events during May 2005 (12-13 May, $\delta^{18} \mathrm{O}=-1.8 \%$; $25 \mathrm{May}, \delta^{18} \mathrm{O}=-1.7 \%$ o). There was very little measurable precipitation in August and therefore a long-term mean value of $0.18 \%$ was used for summer precipitation. Groundwater $\delta^{18} \mathrm{O}$ values are denoted as the monthly mean (solid grey line) $\pm \mathrm{SD}$ (dotted grey lines) of groundwater collected approximately monthly from 2002 through 2006.
Additionally, plants were differently exposed to significant changes in GW utilization from spring to summer. Sites A, $\mathrm{D}$ (located along the extraction line) and B had the strongest reduction in GW use, from spring to summer as indicated by a large seasonal change in xylem water $\delta^{18} \mathrm{O}$ signature.

Such site heterogeneity in GW access and the respective distance to GW levels (Fig. 4) resulted in a very patchy pattern of distance to GW in both seasons (Fig. 4a, b). This spatial heterogeneity between sites was more evident in summer than in spring (Fig. 4a, b).

\subsection{Linking plant functional traits and groundwater use}

An integrated measure of plant water relations and carbon assimilation is given by $\delta^{13} \mathrm{C}$ values of bulk leaf material, which varied significantly between the sites for all species (Table 1a). $\delta^{13} \mathrm{C}$ was similar between seasons for all species except $A$. longifolia, which present some enrichment in $\delta^{13} \mathrm{C}$ during the summer drought compared to the wet spring (Table 1a).

Predawn water potentials ( $\left.\Psi_{\text {pre }}\right)$, as an instantaneous measure of water status, varied significantly between both sites and seasons for some species (Table $1 \mathrm{~b}$ ). $\Psi_{\text {pre }}$ site effects were significant in all species except for the shallow-rooted endemic shrub C. album, which did not significantly alter its water potential in response to the changes in climate conditions (Table 1b).

To investigate the effects of site variation in groundwater access of different co-occurring species and environmental 


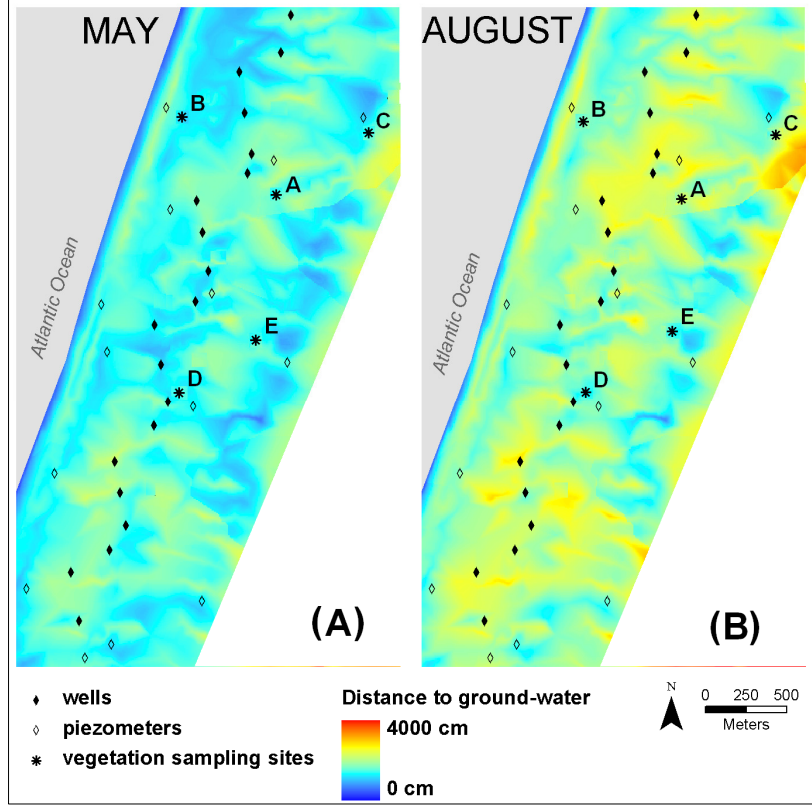

Fig. 4. Maps indicating the depth to groundwater calculated from measurements at wells and piezometers in (A) spring and (B) summer 2005.

conditions, a two-source mixing model (Phillips and Gregg, 2001) was applied, and thus it was possible to determine the percentage of groundwater vs. rainwater used by each species at each site. For all species, with the exception of $C$. album, the percentage of GW used varied significantly across sites, and between the seasons for A. longifiolia and S. repens (Table 1c).

The relationship between relative groundwater use and $\Psi_{\text {pre }}$, measured at the five sites during spring and summer drought, indicated clear differences between species and seasons (Fig. 5a, d). M. faya and S. repens exhibited a significant correlation (Fig. 5a, d; Table 2) between both factors: highest $\Psi_{\text {pre }}$ occurred in site A where plants depended almost solely on GW (>75\%), while the lowest $\Psi_{\text {pre }}$ of $-3.0 \mathrm{MPa}$ occurred in summer in site $\mathrm{E}$ for $M$. faya where there was practically no access to GW (Fig. 5a; Table 2). In fact, S. repens exhibited the highest water potential among all species even during summer and a high proportional GW use, which remained above $50 \% \mathrm{GW}$ use during summer at locations D and $\mathrm{E}$ (Fig. 5d). This reflects the high sensitivity to GW changes by the facultative phreatophyte $S$. repens, tolerating only short periods with no access to GW. In contrast, the alien invasive, A. longifolia had a broad range in GW utilization coupled with the largest variation in predawn water potential; however the response varied substantially between sites (Fig. 5b), with no consistent relationship between GW use and $\Psi_{\text {pre }}$ (Table 2). Furthermore, A. longifolia had the greatest reduction in $\Psi_{\text {pre }}$ of all the species (down to $-3.8 \mathrm{MPa}$ at site B) during summer drought. The drought adapted shrub
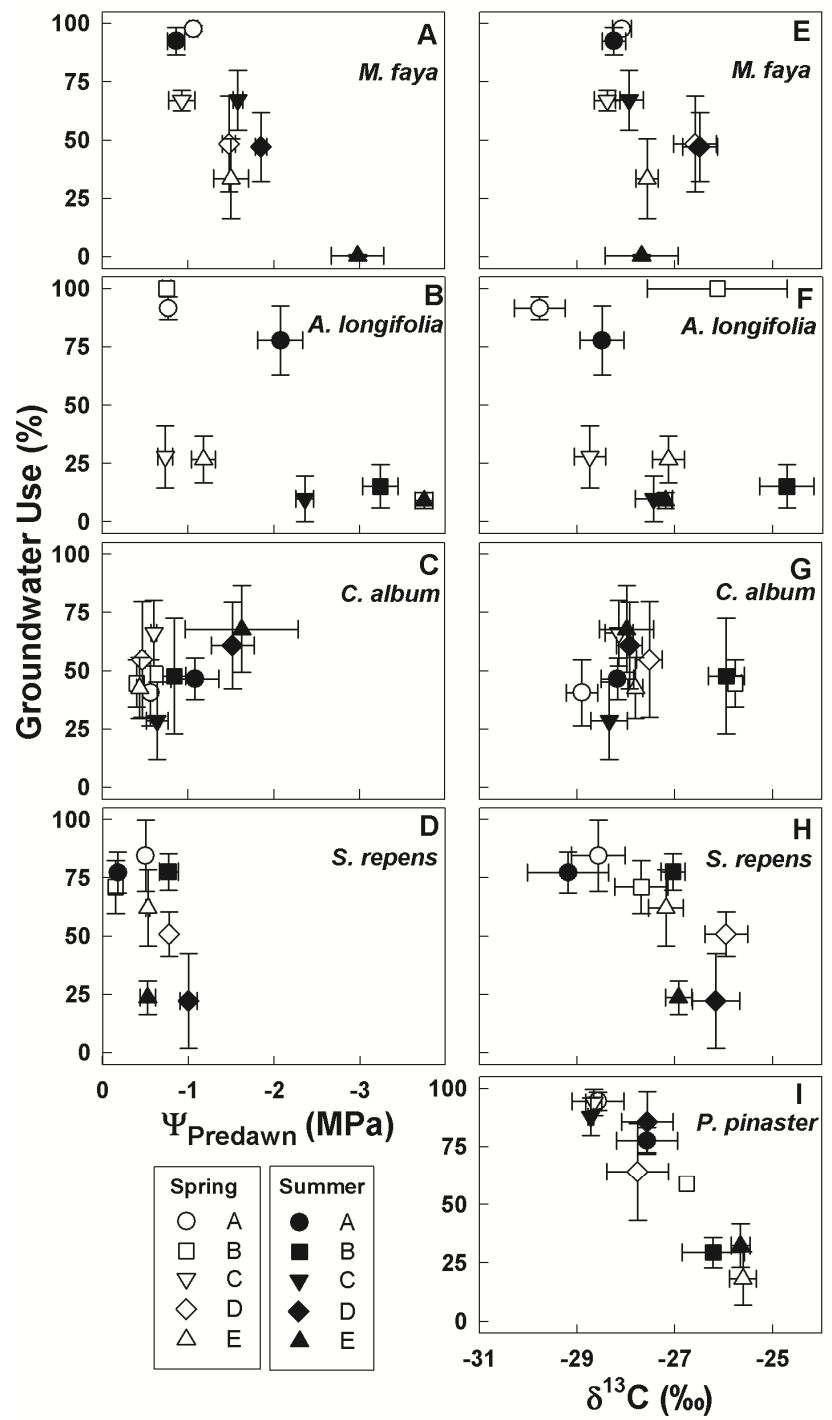

Fig. 5. Relationships between groundwater use (\%), predawn xylem water potential $(\Psi)$ and bulk leaf $\delta^{13} \mathrm{C}(\%)$ for $(\mathbf{A}, \mathbf{E}) M$. faya, (B, F) A. longifolia, $(\mathbf{C}, \mathbf{G})$ C. album, $(\mathbf{D}, \mathbf{H})$ S. repens and (I) $P$. pinaster in spring (open symbols) and summer (closed symbols) at the five sites: A $(\bigcirc)$; B $(\square)$; $(\nabla)$; D $(\diamond)$ and $\mathrm{E}(\triangle)$. Each site is depicted as the mean $\pm \mathrm{SE}$ of groundwater use $(\%)$ against mean \pm SE of bulk leaf $\delta^{13} \mathrm{C}(\%) . n=3-5$ plants for each species and season.

C. album did not present any consistent relationship between GW use and $\Psi_{\text {pre }}$ either (Fig. 5c). For M. faya, S. repens and $P$. pinaster there were significant correlations between bulk leaf $\delta^{13} \mathrm{C}$ values and percentage of GW used in spring as well as for $P$. pinaster during summer (Fig. 5e, h and i; Table 2). Decreasing GW use was associated with an enrichment in leaf $\delta^{13} \mathrm{C}$, reflecting increasing stomatal control of water loss as water availability decreased. This observation was particularly drastic in the case of A. longifolia (Fig. 5f), where a large a variation took place not only between sites but also 
Table 2. Regression coefficients $\left(R^{2}\right)$ for the dependence between groundwater use and (A) bulk leaf $\delta^{13} \mathrm{C}$ and (B) predawn xylem water potential $\left(\Psi_{\text {pre }}\right)$ in spring and summer. Significant regressions $(\alpha=0.05)$ are in bold.

\begin{tabular}{|c|c|c|}
\hline \multirow[t]{2}{*}{ (A) } & \multicolumn{2}{|c|}{ Groundwater Use vs. $\delta^{13} \mathrm{C}$} \\
\hline & Spring & Summer \\
\hline A. longifolia & 0.036 & 0.142 \\
\hline C. album & 0.069 & 0.003 \\
\hline M. faya & 0.258 & 0.016 \\
\hline S. repens & 0.328 & 0.114 \\
\hline$P$. pinaster & 0.337 & 0.553 \\
\hline \multirow[t]{2}{*}{ (B) } & Groundwat & se vs. $\Psi_{\text {pre }}$ \\
\hline & Spring & Summer \\
\hline A. longifolia & 0.073 & 0.142 \\
\hline C. album & 0.015 & 0.001 \\
\hline M. faya & 0.362 & 0.668 \\
\hline S. repens & 0.066 & 0.101 \\
\hline P. pinaster & nd & nd \\
\hline
\end{tabular}

between spring and summer drought. Consistent with the lack of response in $\Psi_{\text {pre }}$ among sites (Fig. 5c), C. album did not have a consistent relationship between $\mathrm{GW}$ use and $\delta^{13} \mathrm{C}$ (Fig. 5g).

\section{Discussion}

This work confirms that groundwater (GW) is an important water source for the functioning and survival of plant communities in coastal sand dunes, and that vegetation may be wholly or partially dependent on GW (e.g. Canadell and Zedler, 1995; Murray et al., 2003; Lite and Stromberg, 2005). Plant species respond to GW changes, showing species-specific responses according to functional traits and site GW access. According to earlier studies (Abrunhosa, 2002), the aquifer at this study site was previously very homogeneous. However, since 2001, water has been continuously extracted from 20 wells within the study area (Fig. 1).

This study highlights the differences between species plasticity which can be seen through the species differences in water-use strategy and GW use. Accordingly, all species, with the exception of the drought adapted shrub C. album, presented a significant difference in $\mathrm{GW}$ use across the five sites depending on the site specific distance to GW (Table 1). Moreover, the increase in xylem water $\delta^{18} \mathrm{O}$ variability (higher enrichment) in all five studied species during summer drought may also be related to a possible higher enrichment in soil water due to higher rates of evaporation from the soil, as observed in other studies (Barnes and Turner, 1998; Querejeta et al., 2007). However, it is not possible to verify this hypothesis since we have used the simplest version of two-ended linear model (Phillip and Gregg 2001) only considering precipitation and GW as possible sources, not soil water. Considering that in a water-stressed environment, the most stable water source is groundwater, we do think that this approach is a good estimation of the main contribution of each water source to meet the water demands of the studied plant species.

In agreement with our original hypothesis, species with deep roots (P. pinaster and M. faya), were the most sensitive to GW drawdown while shallow rooted species (like $C$. album) were less affected by changing GW availability. Both native tree species, $P$. pinaster and $M$. faya, had large variation in GW use across sites (from almost $100 \%$ use to less than $25 \%$ ). The significant regressions between GW use and $\Psi_{\text {pre }}$ and leaf $\delta^{13} \mathrm{C}$ for these species indicated that they responded dynamically to GW availability by regulating carbon assimilation and water use (Fig. 5a, e and i). At sites with ready access to GW, P. pinaster and $M$. faya could use more water, which resulted in increases in $\Psi_{\text {pre. }}$ A very similar pattern was observed for the phreatophyte, S. repens (Fig. 5d).

Variability in the magnitude of physiological adjustments (e.g. changing leaf $\delta^{13} \mathrm{C}$ values and $\Psi_{\text {pre }}$ ) as a result of changes in GW level were observed in the various plant species across the study sites and could furthermore be well related with species-specific phenotypic plasticity. When access to GW was limited (a situation not typically encountered by deep-rooted and phraetophyte species), species such as $P$. pinaster, M. faya and $S$. repens showed a response to water stress conditions, by changing leaf $\delta^{13} \mathrm{C}$ and $\Psi_{\text {pre. }}$. These observations are in agreement with studies demonstrating that $P$. pinaster can be either a drought-avoiding species with high stomatal sensitivity to dry soils (e.g. Férnandez et al., 2000 ), or a drought-tolerant species by making osmotic adjustments, altering biomass partitioning or increasing water use efficiency under drought conditions (Nguyen-Queyrens et al., 1998). An example of extremely high phenotypic plasticity is given by A. longifolia, an exotic-invasive plant species, which is a highly productive, water-spending species (e.g. Peperkorn et al., 2005; Werner et al., 2010), and where it was possible to observe a large variation, in $\delta^{13} \mathrm{C}$ values. This is in agreement with earlier observations, where variations in $\delta^{13} \mathrm{C}$ of plant leaf material, integrates the effects of several functional traits (Werner and Máguas, 2010).

A very different plant response was observed in the evergreen Mediterranean shrub C. album, which presented an irregular pattern and no clear relationship between water potential and GW use (Fig. 5g, Table 2). In fact, this species is of very high importance for the structuring of the dune ridges, and factors other than GW access (e.g. light) most likely led to the wide variation in $\delta^{13} \mathrm{C}$ values. In agreement with other studies (Jackson et al., 1999; Álvarez-Cansino et al., 2010), we showed that, based on their xylem water deuterium values, this evergreen shrub species tended not to use GW sources. 
An interesting observation was that differences in plant responses between sites were more apparent in spring than in summer, reflecting the overall water stress during summer drought, which led to limited metabolic activity in all species. This observation raises an important question: Under extreme drought do plants tend to be stress avoiders (e.g. through dormancy) or do they actively respond by changing physiology and biochemistry, and thus reducing the intensity of the stress? In this study we argue that the exotic invader A. longifolia, which exhibits a water spender strategy (Peperkorn et al., 2005; Rascher et al., 2010, 2011; Werner et al., 2010; Richardson and Pysek, 2006), is the only species that does not present such stress avoider strategy, but a rather highly metabolic stress tolerance response to seasonal drought and site differences (Fig. 5b, f). Indeed, the low values of $\Psi_{\text {pre }}$ for A. longifolia indicate that, irrespective of site GW access, it exhibited little stomatal control of water use. This fits well with recent studies demonstrating that A. longifolia contributes significantly to stand water use in an invaded dune pine forest (up to $42 \%$ seasonally) (Rascher et al., 2011). New leaf growth of the native species typically occurs in a short flush period in spring and early summer, while in A. longifolia growth can extend into the onset of the drought period and more than one flush per year is common. Furthermore, this explains why only A. longifolia presented a significant change in leaf $\delta^{13} \mathrm{C}$ values between spring and summer, emphasizing the very high metabolic activity and the maintenance of carbon assimilation for longer periods than the native species. This indicates that, for the native species, leaves used for determination of $\delta^{13} \mathrm{C}$ values in both seasons may in fact have been from the same cohort of leaves formed during spring thereby resulting in an uncoupling between leaf $\delta^{13} \mathrm{C}$ and xylem water $\delta^{18} \mathrm{O}$ in summer. Therefore, it is not surprising that the correlations between bulk leaf $\delta^{13} \mathrm{C}$ and xylem $\delta^{18} \mathrm{O}$ tended to be stronger in spring than in summer (Fig. 5e-i, Table 2). Overall, $\delta^{13} \mathrm{C}$ was a good indicator of heterogeneity in GW access $(p<0.001$, Table 2$)$, but a poor indicator of seasonal changes (particularly concerning drought) in carbon assimilation. According to recent studies (Werner and Máguas, 2010) $\delta^{13} \mathrm{C}$ of evergreen bulk leaves may integrate not only photosynthetic regulation and water use efficiency, but also a range of other functional traits that determine signatures in leaf structural carbon that is produced during the growing season in spring. Moreover, under conditions when plants are using GW, any decrease in GW use will lead to a strong impact in stomatal regulation, affecting carbon gain. This pattern was particularly evident for species such as P. pinaster, M. faya and S. repens, all of which had either deep root systems or were GW dependent. Thus, it was also clear that this impact was stronger during spring when a high metabolic activity was observed, rather than during summer drought.

In conclusion, this study demonstrates that sand dune communities contain a broad range of plant species with significant differences in functional adaptations. Furthermore, on top of seasonal changes, the dependence on $\mathrm{GW}$ across species and sites is highly variable. Despite the difficulties to acquire information on GW use, and the absence of data on soil water isotopic signature, current mixing models based on $\delta^{18} \mathrm{O}$ values of xylem water yield a means for estimating local GW use. This application of standard mixing models to determine dependence on GW revealed a variety of plant water use strategies which correlated with species functional traits. In accordance with our initial hypotheses, functional traits that lead to direct access to GW such as deep root systems and close contact between roots and the GW table (P. pinaster, M. faya and S. repens) lead to a significant response to changing GW levels. The evergreen shrub $C$. album was the only species in which ecophysiological functioning was completely uncoupled from access to GW. Furthermore our study provides further evidence of the waterspender strategy of the invasive A. longifolia, a trait which distinguishes it from the native vegetation.

Acknowledgements. Financial support was partially provided by Transgás S.A. and REN-Armazenagem contracts, by the Deutsche Forschungsgemeinschaft, (TRANSDUNE Project: \# WE 2681/3-1), Fundação para a Ciência e Tecnologia (POCTI/1999/BSE/34689) and Luso-Alema ICCT/DAAD project (D/02/46225). The authors would like to thank to Paulo Gaspar from REN-Armazenagem for climate, precipitation and piezometric data collection and Rodrigo Maia on isotope analysis. We are also grateful for the assistance of Cristina Antunes in the final version of this manuscript.

Edited by: N. Buchmann

\section{References}

Abrunhosa, M. J.: Projecto de captações em osso da baleia - pombal, Grundfos, 10, 2002.

Alvarez-Cansino, L., Zunzunegui, M., D $\imath$ az Barradas, M. C., and Esquivias M. P.: Physiological performance and xylem water isotopic composition underlie gender-specific responses in the dioecious shrub Corema album, Physiologia Plantarum, 140, 32-45, 2010.

Antonellini, M. and Mollema, P.: Impact of groundwater salinity on vegetation species richeness in the coastal pine forests and wetlands of Ravenna, Italy. Ecological Engineering, 30, 12011211, doi:10.1016/j.ecoleng.2009.12.007, 2010.

Barnes, C. and Turner, J.: Isotopic exchange in soil water, in: Isotopes tracers in catchment hydrology, edited by: Kendall C, M. J., Elsevier, Amsterdam, 1998.

Brolsma, R., van Beek, R., and Bierkens, M. F. P.: Vegetation competition model for water and light limitation II: Spatial dynamics of groundwater and vegetation, Ecol. Modell., 221, 1364-1377, 2010.

Canadell, J. and Zedler, P.: Underground structures of woody plants in Mediterranean ecosystems of Australia, California and Chile, In: Ecology and Biogeography of Mediterranean Ecosystems in Chile, California and Australia, edited by: Fox, M., Kalin, M., and Zedler, P., Springer-Verlag, Berlin, 177-210, 1995. 
Canadell, J., Jackson, R. B., Ehleringer, J. R., Mooney, H. A., Sala, O. E., and Schulze, E. D.: Maximum rooting depth of vegetation types at the global scale, Oecologia, 108, 583-595, 1996.

CERENA : Centro de Recursos Naturais e Ambiente : GeoMS Geostatistical Modelling Software, 2000.

Corbin, J., Thomsen, M., Dawson, T., and D'Antonio, C.: Summer water use by California coastal prairie grasses: fog, drought, and community composition, Oecologia, 145, 511-521, doi:10.1007/s00442-005-0152-y, 2005.

Costelloe, J. F., Payne, E., Woodrow, I. E., Irvine, E. C., Western, A. W., and Leaney, F. W.: Water sources accessed by arid zone riparian trees in highly saline environments, australia, Oecologia, 156, 43-52, doi:10.1007/s00442-008-0975-4, 2008.

Dawson, T. E. and Ehleringer, J. R.: Streamside trees that do not use stream water, Nature, 350, 335-337, 1991.

Dawson, T. E.: Water sources of plants as determined from xylemwater isotopic composition: Perpectives on plant competition, distribution and water relations, in: Stable isotopes and plant carbon-water relations, edited by: Ehleringer, J., Hall, A., and Farquhar, G., Academic Press, San Diego, 465-496, 1993.

Dawson, T. E. and Pate, J. S.: Seasonal water uptake and movement in root systems of australian phraeatophytic plants of dimorphic root morphology: A stable isotope investigation, Oecologia, 107, 13-20, 1996.

Ehleringer, J. R. and Dawson, T. E.: Water-uptake by plants - perspectives from stable isotope composition, Plant Cell and Environment, 15, 1073-1082, 1992.

ESRI (2008) ArcMap ver. 9.2., 2008.

Fernández, M., Gil, L., and Pardos, J. A.: Effects of water supply on gas exchange in Pinus Pinaster Ait. provenance during their first growing season, Ann. For. Sci., 57, 9-16, 2000.

Garcia Novo, F., Diaz-Barradas, M. C., Zunzunegui, M., Garcia Mora, R., and Gallego Fernandez, J. B.: Plant functional types in coastal dune habitats, in: Ecological Studies, edited by: Martinez, M. L., Psuty, N. P., Berlin, Springer-Verlag, 171, 155-169, 2004.

Hinckley, T., Richter, H., and Schulte, P.: Water relations, in: Physiology of trees, edited by: AS, R., Wiley, New York, 137-162, 1991.

Jackson, P. C., Cavelier, J., Goldstein, G., Meinzer, F. C., and Holbrook, N. M.: Partitioning of water-resources among plants of a lowland tropical forest, Oecologia, 101, 197-203, 1995.

Jackson, P. C., Meinzer, F. C., Bustamante, M., Goldstein, G., Franco, A., Rundel, P. W., Caldas, L., Igler, E., and Causin, F.: Partitioning of soil water among tree species in a brazilian cerrado ecosystem, Tree Physiology, 19, 717-724, 1999.

Jackson, R. B., Sperry, J. S., and Dawson, T. E.: Root uptake and transport: using physiological processes in global predictions, Trends Plant Sci., 5, 481-488, 2000.

Lamontagne, S., Cook, P. G., O'Grady, A., and Eamus, D.: Groundwater use by vegetation in a tropical savanna riparian zone (daly river, australia), J. Hydrol., 310, 280-293, doi:10.1016/j.jhydrol.2005.01.009, 2005.

Lite, S. J. and Stromberg, J. C.: Surface water and groundwater thresholds for maintaining populus-salix forests, san pedro river, arizona, Biological Conservation, 125, 153-167, doi:10.1016/j.biocon.2005.01.020, 2005.

Murray, B. R., Zeppel, M. J. B., Hose, G. C., and Eamus, D.: Groundwater-dependent ecosystems in australia: It's more than just water for rivers, Ecol. Manage. Restor., 4, 4, 2003.

Nguyen-Queyrens, A., Ferhi, A., Loustau, D., and Guehl, J. M.: Within-ring delta $\mathrm{C}-13$ spatial variability and interannual variations in wood cellulose of two contrasting provenances of Pinus pinaster, Can. J. For. Res., 28, 766-773, 1998.

Peperkorn, R., Werner, C., and Beyschlag, W.: Phenotypic plasticity of an invasive Acacia versus two native Mediterranean species, Funct. Plant Biol., 32, 933-944, doi:10.1071/FP04197, 2005.

Phillips, D. L. and Gregg, J. W.: Uncertainty in source partitioning using stable isotopes, Oecologia, 127, 171-179, 2001.

Querejeta, J. I., Estrada-Medina, H., Allen, M. F., and JimenezOsornio, J. J.: Water source partitioning among trees growing on shallow karst soils in a seasonally dry tropical climate, Oecologia, 152, 26-36, doi:10.1007/s00442-006-0629-3, 2007.

Rascher, K. G., Máguas, C., and Werner, C.: On the use of phloem sap $\delta^{13} \mathrm{C}$ as an indicator of canopy carbon discrimination, Tree Physiology, 30, 1499-1514, doi:10.1007/s10530-0119949-2, 2010.

Rascher, K. G., Gro $\beta$ e-Stoltenberg, A., Máguas, C., and Werner, C.: Understory invasion by Acacia longifolia alters the water balance and carbon gain of a Mediterranean pine forest, Ecosystems, 14, 904-919, doi:10.1007/s10021-011-9453-7, 2011.

Richardson, D. M. and Pyšek, P.: Plant invasions: merging the concepts of species invasiveness and community invasibility, Progr. Phys. Geogr, 30, 409-431, 2006.

Rosenthal, D. M., Ludwig, F., and Donovan, L. A.: Plant responses to an edaphic gradient across an active sand dune/desert boundary in the great basin desert, Int. J. Plant Sci., 166, 247-255, 2005.

Scholander, P. F., Hammel, H. T., Bradstreet, E. D., Hemmingsen, E. A.: Sap pressure in vascular plants, Science, 148, 339-346, 1965.

Stratton, L. C., Goldstein, G., and Meinzer, F. C.: Temporal and spatial partitioning of water resources among eight woody species in a hawaiian dry forest, Oecologia, 124, 309-317, 2000.

Stromberg, J. C. and Patten, D. T.: Riparian vegetation instream flow requirements - a case-study from a diverted stream in the eastern sierra-nevada, california, usa, Environ. Manage., 14, 185-194, 1990.

Stromberg, J. C., Tiller, R., and Richter, B.: Effects of groundwater decline on riparian vegetation of semiarid region: The San Pedro River, Arizona, Ecol. Appl., 6, 113-131, 1996.

Valentini, R., Mugnozza, G. S., Deangelis, P., and Matteucci, G.: Coupling water sources and carbon metabolism of natural vegetation at integrated time and space scales, Agr. Forest Meteorol., 73, 297-306, 1995.

Xie, T., Liu, X., and Sun, T.: The effects of groundwater table and flood irrigation strategies on soil water and salt dynamics and reed water use in the Yellow River Delta, China, Ecol. Modell., 222, 241-252, 2011.

Werner, C. and Máguas, C.: Carbon isotope discrimination as a tracer of functional traits in a Mediterranean macchia plant community, Funct. Plant Biol., 37, 467-477, doi:10.1071/FP09081, 2010.

Werner, C., Zumkier, U., Beyschlag, W., and Máguas, C.: High competitiveness of a resource demanding invasive acacia under low resource supply, Plant Ecol., 206, 83-96, doi:10.1007/s11258-009-9625-0, 2010. 
White, J. W. C., Cook, E. R., Lawrence, J. R., and Broecker, W. S.: The $\mathrm{d} / \mathrm{h}$ ratios of sap in trees - implications for water sources and tree-ring d/h ratios, Geochim. Cosmochim. Ac., 49, 237246, 1985.

Yurtsever, Y. and Gat, J. R.: Stable Isotope hydrology IAEA Tech, edited by: Gat, J. R. and Gonfiantini, R., Rep. Ser, 210, 103-142, 1981.
Zunzunegui, M., Barradas, M. C. D., Ain-Lhout, F., Clavijo, A., and Novo, F. G.: To live or to survive in donana dunes: Adaptive responses of woody species under a mediterranean climate, Plant Soil, 273, 77-89, doi:10.1007/s11104-004-6806-4, 2005.

Zunzunegui, M., Diaz Barradas, M. C., Ain-Lhout, F., Cansino, L. A., Esquivias. M. P., and Novo, F. G.: Seasonal physiological plasticity and recovery capacity after summer stress in Mediterranean scrub communities, Plant Ecol., 212, 127-142, 2011. 